\title{
Effects of weight loss on liver and erythrocyte polyunsaturated fatty acid pattern and oxidative stress status in obese patients with non-alcoholic fatty liver disease
}

\author{
ALEJANDRA ELIZONDO ${ }^{1}$, JULIA ARAYA ${ }^{1}$, RAMÓN RODRIGO ${ }^{2}$, CINZIA $^{2}$ \\ SIGNORINI $^{3}$, CRISTIANA SGHERRI $^{3}$, MARIO COMPORTI ${ }^{3}$, JAIME PONIACHIK $^{4}$ \\ and LUIS A VIDELA ${ }^{2}$
}

\footnotetext{
${ }^{1}$ Department of Nutrition, Faculty of Medicine, Universidad de Chile, Chile

${ }^{2}$ Molecular and Clinical Pharmacology Program, Institute of Biomedical Sciences, Faculty of Medicine, Universidad de Chile, Chile

${ }^{3}$ Department of Physiopathology, Experimental Medicine and Public Health, Università degli Studi di Siena, Italy

${ }^{4}$ Department of Medicine, Gastroenterology Center, Universidad de Chile Clinical Hospital, Chile
}

\begin{abstract}
Our aim was to study the influence of weight loss on the fatty acid (FA) composition of liver and erythrocyte phospholipids and oxidative stress status in obese, non-alcoholic, fatty liver disease (NAFLD) patients. Seven obese NAFLD patients who underwent subtotal gastrectomy with a gastro-jejunal anastomosis in roux and Y were studied immediately and 3 months after surgery. Seven non-obese patients who underwent anti-reflux surgery constituted the control group. Serum $\mathrm{F}_{2}$-isoprostane levels were measured by GS/NICI-MS/MS and FA composition was determined by GC. At the time of surgery, controls and obese patients exhibited a hepatic polyunsaturated fatty acid (PUFA) pattern that correlated with that of erythrocytes. Three months after surgery, NAFLD patients lost $21 \%$ of initial body weight; serum $\mathrm{F}_{2}$-isoprostane levels decreased by $76 \%$; total PUFA, long-chain PUFA (LCPUFA), n-3 PUFA, and n-3 LCPUFA increased by 22, 29, 81, and 93\%, respectively; n-6/n-3 LCPUFA ratio decreased by $51 \%$; docosahexaenoic acid/docosapentaenoic acid ratio increased by 19 -fold; and the $n-3$ product/precursor ratio $(20: 5+22: 5+22: 6) / 18: 3$ increased by $164 \%$ $(\mathrm{p}<0.05)$. It is concluded that weight loss improves the n-3 LCPUFA status of obese patients in association with significant amelioration in the biomarkers of oxidative stress, membrane FA insaturation, and n-3 LCPUFA biosynthesis capacity, thus representing a central therapeutic issue in the improvement of obesityrelated metabolic alterations involved in the mechanism of hepatic steatosis.
\end{abstract}

Key terms: polyunsaturated fatty acids, oxidative stress, obesity, weight loss.

\section{INTRODUCTION}

Non-alcoholic fatty liver disease (NAFLD) is becoming a major cause of chronic liver disease in relation to the increasing prevalence of obesity and type- 2 diabetes in the general population. In the setting of obesity, NAFLD encompasses a wide disease spectrum including triacylglycerol (TAG) accumulation in hepatocytes (steatosis) and steatosis with inflammation, fibrosis, and cirrhosis (non-alcoholic steatohepatitis, NASH) (Angulo, 2006). These hepatic alterations are related to insulin resistance and oxidative stress as crucial pathogenic factors (Videla et al., 2004a; Angulo, 2006), phenomena that show interdependency (Videla et al., 2006). In particular, hepatic steatosis can be influenced by insulin resistance through

Corresponding Author: Luis A. Videla, Programa de Farmacología Molecular y Clínica, Instituto de Ciencias Biomédicas, Facultad de Medicina, Universidad de Chile, Casilla 70000, Santiago-7, Chile; Tel: 56-2-9786256; Fax: 56-2-7372783; E-mail: lvidela@med.uchile.cl 
induction of a higher peripheral lipolysis with enhanced fluxes of fatty acids (FA) and glycerol to the liver, thus favouring lipogenesis (Saltiel \& Khan, 2001). Oxidative stress associated with NAFLD in obese patients represents a nutritional type of phenomenon, resulting from prolonged excess oxidative load (carbohydrates, lipids) and inadequate nutrient supply (dietary antioxidants) favoring pro-oxidant reactions (Sies et al., 2005). Promotion of long-chain polyunsaturated FA (LCPUFA) peroxidation by oxidative stress (Fernández \& Videla, 1996; Videla et al., 2004b) may also favor lipogenesis through LCPUFA depletion, particularly those of the n-3 series (Araya et al., 2004). LCPUFA are known to regulate hepatic lipid metabolism by modulating related enzyme expression at the level of gene transcription, mRNA processing and decay, and post-translational protein modifications, directing FA away from TAG storage and into oxidation and secretion (Clarke, 2004).

Depletion of n-3 LCPUFA in NAFLD is related to several factors, in addition to increased peroxidation by oxidative stress (Araya et al., 2004). These include (i) defective dietary intake of n-3 LCPUFA and of their essential precursor a-linolenic acid (18: 3 n-3) (Baylin et al., 2002); evidenced by their lower adipose tissue levels (Araya et al., 2004); (ii) defective desaturation and elongation of PUFA evidenced by the lower liver product/ precursor ratio $(20: 5+22: 6) n-3 / 18: 3 n-3$; and/or (iii) higher dietary intake of trans FA such as elaidic acid (18: 1 n-9 trans) (Araya et al., 2004), exerting substantial inhibition of hepatic delta-6 desaturase activity (Das, 2005). Recently, the changes in the LCPUFA pattern observed in the liver from obese patients were found significantly correlated with those in erythrocyte phospholipids (Elizondo et al., 2007). These data suggest that erythrocyte FA composition could be a reliable biomarker of the derangements in liver lipid metabolism leading to steatosis in obese patients (Elizondo et al., 2007), a feature that showed major improvements with weight loss induced by bariatric surgery (Dixon et al., 2004; Klein et al., 2006;
Mathurin et al., 2006). In view of these considerations, we tested the hypothesis that depletion of n-3 LCPUFA and enhancement in the oxidative stress status of obese NAFLD patients immediately after surgery are ameliorated upon weight loss. For this purpose, LCPUFA composition was determined in liver and erythrocyte phospholipid fractions in relation to the serum levels of $\mathrm{F}_{2}$-isoprostanes as index of oxidative stress, both in obese NAFLD patients at surgery and three months after subtotal gastrectomy.

\section{MATERIALS AND METHODS}

\section{Patients and laboratory investigations}

Fourteen subjects who received treatment at the Department of Medicine of the Universidad de Chile Clinical Hospital were studied, including seven NAFLD patients [average body mass index (BMI) of $45.4 \pm$ $2.2 \mathrm{~kg} / \mathrm{m}^{2}$, age range of $28-56$ years], who underwent subtotal gastrectomy with a gastro-jejunal anastomosis in roux and $\mathrm{Y}$ as a therapy for obesity, and seven non-obese patients [BMI of $22.4 \pm 0.6 \mathrm{~kg} / \mathrm{m}^{2}$, aged between 23 and 60 years] who underwent anti-reflux surgery (control group). The protocol was explained in detail to the subjects, who then gave their written informed consent to participate in the study before any procedure was undertaken. Exclusion criteria included positive hepatitis $\mathrm{B}$ or $\mathrm{C}$ serology, positive antibodies (antinuclear, anti-mitochondrial, and antismooth muscle antibodies), smoking habits or nonsmokers <1 year cessation, and consumption of more than $40 \mathrm{~g}$ of ethanol per week. Nutritional and alcohol consumption histories with anthropometric measurements were obtained. Insulin resistance was calculated from the fasting insulin and glucose values by homeostasis model assessment (HOMA) of insulin resistance analysis [fasting insulin (munits/ $\mathrm{ml}) \mathrm{x}$ fasting glucose $(\mathrm{mmol} / \mathrm{l}) / 22.5]$ (Matthews et al., 1985) [Controls, $2.0 \pm 0.2$ $(\mathrm{n}=7) \mathrm{kg} / \mathrm{m}^{2}$; NAFLD patients, $9.6 \pm 3.0$; $\mathrm{P}<0.05$ assessed by Mann-Whitney $\mathrm{U}$ test]. Both plasma lipid levels (total cholesterol, 
HDL-cholesterol, LDL-cholesterol, and triacylglycerols) and ALT activity in serum were within normal ranges in the studied groups; two NAFLD patients exhibited serum AST levels >40 IU/1 (57-254 IU/1).

The patients were subjected to a diet of $25 \mathrm{kcal} / \mathrm{kg}$ body weight (where $1 \mathrm{kcal}=$ $4.184 \mathrm{~kJ}$ ), with $30 \%$ of the energy given as lipids and $15 \%$ as proteins, for at least 2 days prior to surgery, and liver tissue of approximately $2 \mathrm{~cm}^{3}$ for histological diagnoses and lipid composition determination were taken during surgery. The samples were fixed in $10 \%$ formalin, paraffin embedded, and sections were stained with hematoxylin/eosin and Van Gieson's stains. Sections of each liver sample were observed in a blinded manner and evaluated for histological alterations by means of previously defined codes (Das \& Kar, 2005). Control patients exhibited a normal liver histology, whereas obese patients showed the presence of macrovesicular steatosis. In the latter group, six patients exhibited steatosis alone, and one patient presented steatosis and lobular inflammation with hepatocyte ballooning (steatohepatitis). Considering that changes in the hepatic composition of n-6 and n-3 PUFA is comparable in obese NAFLD patients with steatosis or steatohepatitis (Araya et al., 2004), all obese patients studied were joined in a single group. The Ethics Committee of the Universidad de Chile Clinical Hospital and that of the Faculty of Medicine, Universidad de Chile, approved the study protocol, which was performed in accordance with the Helsinki Declaration II criteria.

Preparation procedure and gas-mass analysis for plasma $\mathrm{F}_{2}$-isoprostane determination

Venous blood drawn from controls and NADLF patients was collected in apyrogenic EDTA-tubes before and three months after surgery in NAFLD patients. Samples were fractioned for determination of either erythrocyte FA composition or serum $\mathrm{F}_{2^{-}}$ isoprostane levels, the latter collected in tubes containing $1 \mathrm{mM}$ butylated hydroxytoluene. The samples were stored at $-80^{\circ} \mathrm{C}$. The preparation of serum samples prior to gas-mass analysis of $\mathrm{F}_{2}$-isoprostanes involved solid-phase extraction on an octadecylsilane $\left(\mathrm{C}_{18}\right)$ and silica cartridge followed by thin-layer chromatography (TLC), combined with aminopropyl $\left(\mathrm{NH}_{2}\right)$ cartridge solid-phase extraction (Signorini et al., 2003). The determinations were carried out by gas chromatography/negative ion chemical ionization tandem mass spectrometry (GS/NICI-MS/MS) analysis. Samples $(1 \mathrm{ml})$ were injected into the gas chromatograph in undecane containing N,Obis-(trimethylsilyl)trifluoroace tamide (BSTFA). The carrier gas was helium, and methane was used as reagent gas at a flow of $1.2 \mathrm{ml} / \mathrm{min}$. The collision energy used was $1.3 \mathrm{eV}$. The measured ions were $\mathrm{m} / \mathrm{z} 299$ and $\mathrm{m} / \mathrm{z} 303$ derived from the typical ions $(\mathrm{m} / \mathrm{z}$ 569 and $\mathrm{m} / \mathrm{z} 573$ ) produced from $15-\mathrm{F}_{2 \mathrm{t}}$-IsoP (the most represented isomer) and the tetradeuterated derivative of $\mathrm{PGF}_{2 \mathrm{a}}$, respectively. The detection limit was $10 \mathrm{pg} /$ $\mathrm{ml}(0.028 \mathrm{nM})$.

\section{Extraction and separation of liver and erythrocyte membrane phospholipids}

Liver tissue dissociation was achieved by homogenization in ice-cold chloroformmethanol $(2: 1, \mathrm{v} / \mathrm{v})$ containing $0.01 \%(\mathrm{w} / \mathrm{v})$ butylated hydroxytoluene using an Ultraturrax homogenizer (Janke \& Kunkel, Stufen, Germany). Phospholipids from liver were separated by thin-layer chromatography (TLC) aluminum sheets $(20$ x $20 \mathrm{~cm}$ silica gel 60 F-254; Merck, Santiago, Chile), using a solvent system of hexane/diethyl ether/acetic acid (80: 20: 1, by vol.) and phosphatidylcholine as standard (Skipski et al., 1964). After development of the plate, the solvent was allowed to evaporate, and lipid bands were visualized by exposing the plates to Camag UV (250 nm) lamp designed for use in the TLC laboratory. This solvent system separates phospholipids, cholesterol, triacylglycerols, and cholesterol esters in increasing order of relative mobility. Individual lipid zones were scraped from TLC plates and eluted from the silica gel with chloroform/methanol/water (10: 10: 1, by vol.) (Ruiz-Gutiérrez et al., 1992). 
Blood samples drawn in vacutainers containing $5 \%(\mathrm{w} / \mathrm{v})$ EDTA as anticoagulant were centrifuged at $1800 \mathrm{~g}$ and $4{ }^{\circ} \mathrm{C}$ for 15 minutes to separate erythrocytes. Erythrocyte membranes were obtained according to Huertas et al. (1998), and membrane lipids were extracted as described by Bligh and Dyer (1959). Separation of phospholipid fractions was performed as described for liver phospholipids.

Preparation and analysis of fatty acid methyl esters (FAME)

Fatty acids from liver phospholipids and from erythrocyte membranes were methylated. The phospholipids were eluted from silica gel with two $15-\mathrm{ml}$ portions of chloroform/methanol/water (10: 10: 1 , by vol). The solvent was evaporated in a nitrogen stream, and $10 \mathrm{mg}$ of tricosaenoic acid (23: 0, internal standard) was added prior to the esterification with $0.2 \mathrm{~N}$ sodiummethanol during 30 minutes at $40^{\circ} \mathrm{C}$, and then, with $\mathrm{H}_{2} \mathrm{SO}_{4}$ methanol as described for alkaline methylation. After the sample was cooled, the fatty acid methyl esters (FAME) were extracted with $0.5 \mathrm{ml}$ hexane. FAME of all samples were analyzed by gas-liquid chromatography (GC). A Hewlett-Packard gas chromatograph (model 6890), equipped with a capillary column $(50 \mathrm{~m} \times 0.22 \mathrm{~mm}$ BPX70; $0.25 \mathrm{U}$ QC 0.08 SGE), was employed to separate FAME. The temperature was programmed from 180 to $230^{\circ} \mathrm{C}$ at $2{ }^{\circ} \mathrm{C} / \mathrm{min}$ with a final hold, separating 12: 0 to 22: 6,n-3. The temperature of both detector and injector was $240^{\circ} \mathrm{C}$. Hydrogen was used as carrier gas, at a flow rate of $1.5 \mathrm{ml} / \mathrm{min}$ and split ratio of 1: 80 . The FAME were identified by comparison of their retention times with those of individual purified standards and quantified using a Hewlett-Packard integrator (HP 3396 Series III) (Araya et al., 2001).

\section{Statistical analysis}

Results are expressed as means \pm SEM for the number of patients indicated. Statistical analysis of the differences between mean values from control subjects and obese NAFLD patients immediately after surgery was assessed by the nonparametric MannWhitney U test, whereas that between patients with NAFLD immediately after surgery and three months post-surgery was performed by Wilcoxon test. The differences were considered statistically significant at $p<0.05$. To analyze the association between different variables, the Spearman rank order correlation coefficient was used. All statistical analyses were computed using GraphPad Prism ${ }^{\mathrm{TM}}$ version 2.0 (GraphPad Software Inc., San Diego, CA, USA).

\section{RESULTS}

Obese patients at surgery exhibited average BMI values (Fig. 1A) and serum $\mathrm{F}_{2}$ isoprostane levels (Fig. 1B) $103 \%$ and $98 \%$ higher than those in non-obese controls $(\mathrm{p}<0.05)$, respectively. Three months after surgery, obese patients showed $60 \%$ and $23 \%$ decrease in $\mathrm{BMI}$ and serum $\mathrm{F}_{2}$ isoprotane levels over control values (Fig. $1 \mathrm{~A}$ and $1 \mathrm{~B})$, thus representing a net $41 \%$ and $76 \%$ reduction, respectively $(\mathrm{p}<0.05)$ (Fig. 1).

Data presented in Table I show significant decreases in the content of 18: 2 n-6, 20: 4 n-6, 20: 5 n-3, 22: 5 n-3, and 22: 6 $\mathrm{n}-3$ in liver phospholipids from obese patients at the time of surgery over control values, with a marked enhancement in that of 22: 5 n-6. The above data represent no significant changes in n-6 PUFA (Fig. 2A) and n-6 LCPUFA (Fig. 2B) in control and NAFLD patients. However, in obese patients, total PUFA and total LCPUFA were $38 \%$ lower (Fig. 2A and 2B); n-3 PUFA and n-3 LCPUFA were 59\% lower (Fig. 2A and 2B); the n-6/n-3 LCPUFA ratio was $113 \%$ higher (Fig. 2C); and the DHA/ DPA n-6 ratio was $93 \%$ lower (Fig. 2D) than control values. The product/precursor ratio $(20: 5+22: 5+22: 6)$ n-3/18: 3 n-3 was $45 \%$ lower in the liver of NAFLD patients over control values (controls, $24.6 \pm 8.2$ $[\mathrm{n}=7])$; obese patients immediately after surgery, $13.4 \pm 3.3[\mathrm{n}=7] ; \mathrm{p}<0.05)$ (from Table I). 

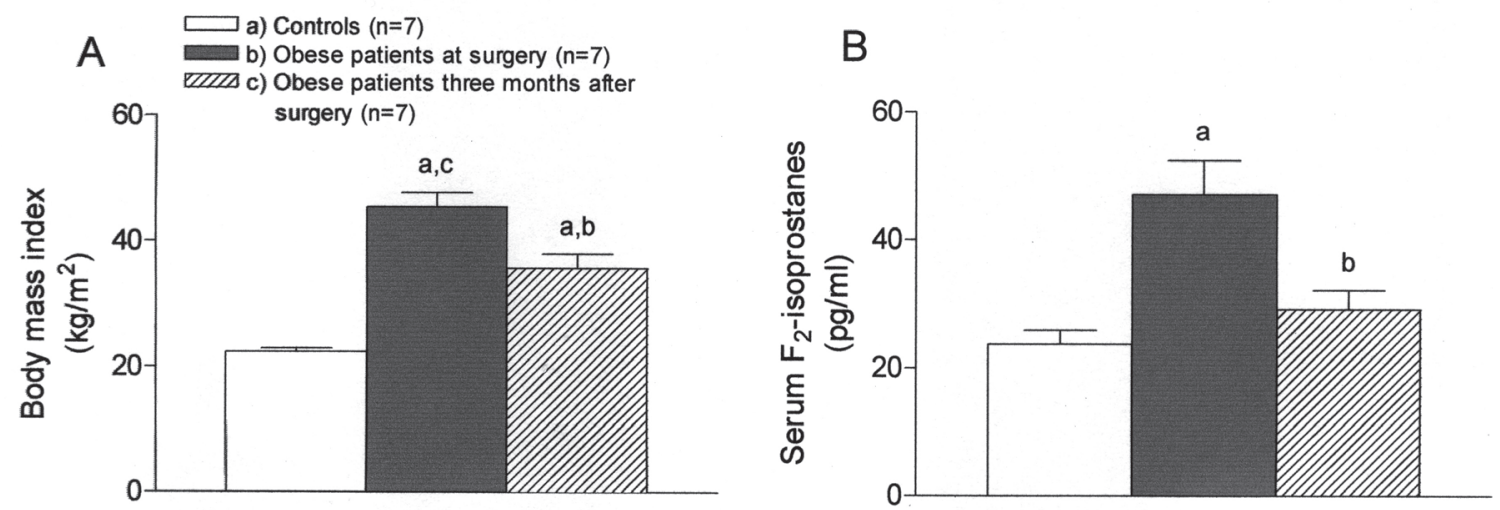

Figure 1: Body mass index (A) and serum $F_{2}$-isoprostane levels (B) in control subjects and in obese patients with non-alcoholic fatty liver disease at the time of surgery and three months after surgery. Values represent means \pm SEM for the number of patients indicated in parenthesis. Significant differences between mean values are indicated by the letters identifying each group: ${ }^{a} \mathrm{p}<0.05$ versus controls (Mann-Whitney $\mathrm{U}$ test); ${ }^{\mathrm{b}} \mathrm{p}<0.05$ versus obese patients at the time of surgery (Wilcoxon test); ${ }^{c} \mathrm{p}<0.05$ versus obese patients three months after surgery (Wilcoxon test).

TABLE I

Polyunsaturated fatty acid (PUFA) composition of liver phospholipids in control subjects and obese patients with non-alcoholic fatty liver disease (NAFLD) at the time of surgery

\begin{tabular}{lccc}
\hline $\begin{array}{l}\text { PUFA } \\
(\mathrm{g} / 100 \mathrm{~g} \text { of FAME) }\end{array}$ & $\begin{array}{c}\text { Controls } \\
(\mathrm{n}=7)\end{array}$ & $\begin{array}{c}\text { NAFLD patients } \\
(\mathrm{n}=7)\end{array}$ & \% Change \\
\hline $18: 2 \mathrm{n}-6$ & $1.68 \pm 0.21$ & $0.89 \pm 0.21$ & $-47^{\mathrm{b}}$ \\
$18: 3 \mathrm{n}-3$ & $1.03 \pm 0.16$ & $0.77 \pm 0.07$ & -25 \\
$20: 4 \mathrm{n}-6(\mathrm{ARA})^{\mathrm{c}}$ & $20.0 \pm 0.4$ & $10.2 \pm 0.9$ & $-49^{\mathrm{b}}$ \\
$20: 5 \mathrm{n}-3(\mathrm{EPA})^{\mathrm{c}}$ & $4.58 \pm 0.50$ & $2.14 \pm 0.35$ & $-53^{\mathrm{b}}$ \\
$22: 5 \mathrm{n}-6(\mathrm{DPA})^{\mathrm{c}}$ & $1.95 \pm 0.09$ & $8.89 \pm 1.99$ & $355^{\mathrm{b}}$ \\
$22: 5 \mathrm{n}-3(\mathrm{DPA})^{\mathrm{c}}$ & $5.87 \pm 0.72$ & $3.33 \pm 0.80$ & $-43^{\mathrm{b}}$ \\
$22: 6 \mathrm{n}-3(\mathrm{DHA})^{\mathrm{c}}$ & $14.9 \pm 0.7$ & $4.88 \pm 0.98$ & $-67^{\mathrm{b}}$ \\
\hline
\end{tabular}

Values represent means \pm SEM for the number of patients indicated.

${ }^{a}$ FAME, fatty acid methyl esters.

${ }^{b} \mathrm{p}<0.05$ compared to control values, assessed by Mann-Whitney U test.

c ARA, arachidonic acid; EPA, eicosapentaenoic acid; DPA, docosapentaenoic acid; DHA, decosahexaenoic acid. 

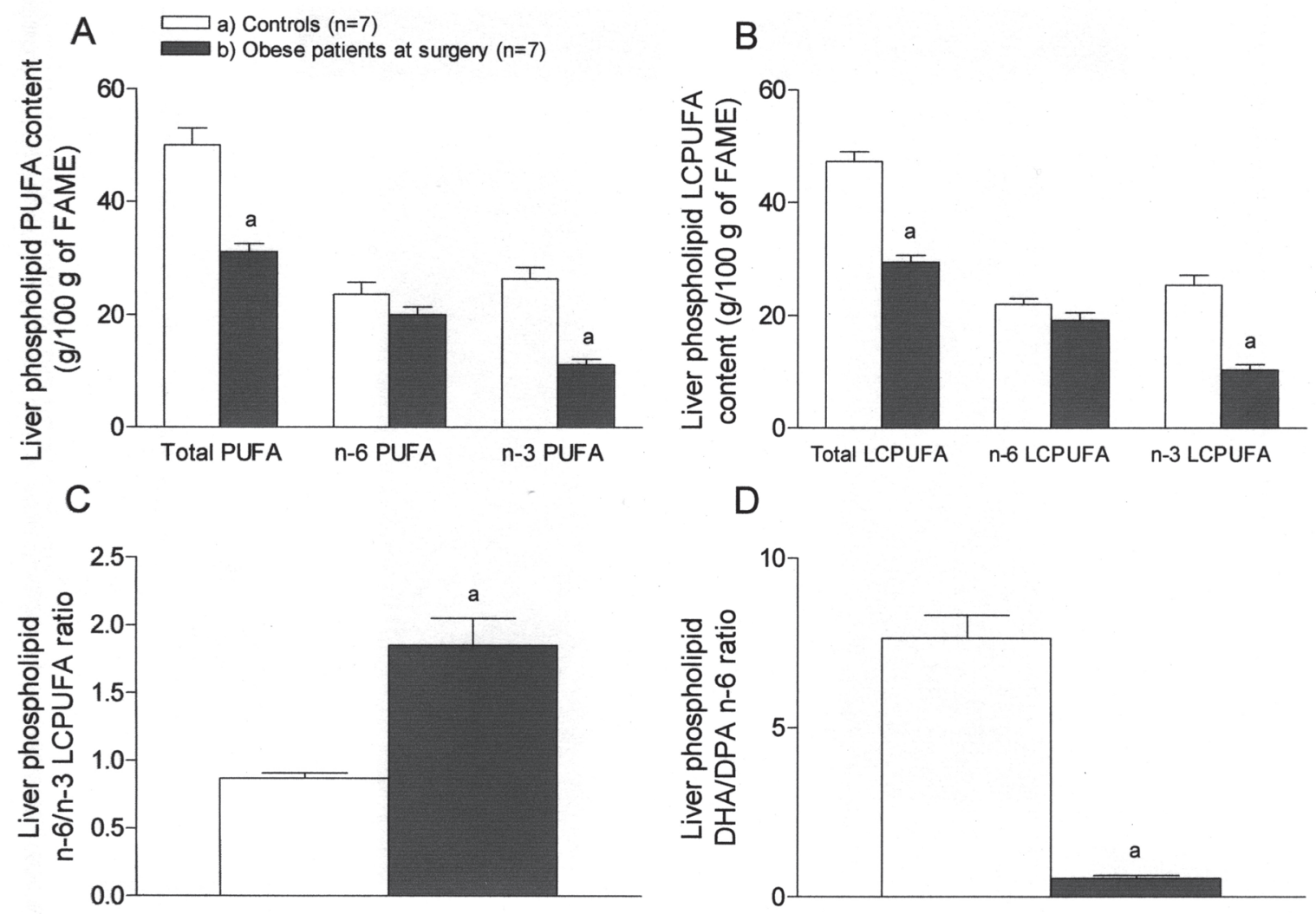

Figure 2: Polyunsaturated fatty acid (PUFA) content (A), long-chain PUFA (LCPUFA) content (B), n-6/n-3 LCPUFA ratio (C), and docosahexaenoic acid (DHA)/docosapentaenoic acid (DPA n6) ratio (D) in liver phospholipids from control subjects and obese patients with non-alcoholic fatty liver disease at the time of surgery. Values represent means \pm SEM for the number of patients indicated in parenthesis. Significant differences between mean values are indicated by the letters identifying each group: ${ }^{a} \mathrm{p}<0.05$ versus controls (Mann-Whitney U test). Abbreviations: FAME, fatty acid methyl esters; total PUFA are 18: 2 n-6, 18: 3 n-3, 20: 4 n-6, 20: 5 n-3, 22: 5 n-6 (DPA n6), 22: 5 n-3, and 22: 6 n-3 (DHA); n-6 PUFA are 18: 2 n-6, 20: 4 n-6, and 22: 5 n-6; n-3 PUFA are 18: 3 n-3, 20: 5 n-3, 22: 5 n-3, and 22: 6 n-3; total LCPUFA are 20: 4 n-6, 20: 5 n-3, 22: 5 n-6, 22: 5 n-3, and 22: 6 n-3; n-6 LCPUFA are 20: 4 n-6 and 22: 5 n-6; n-3 LCPUFA are 20: 5 n-3, 22: 5 n3, and 22: $6 \mathrm{n}-3$.

The fatty acid composition of erythrocyte phospholipids was comparable in 18: 3 n-3 and 20: 5 n-3 levels in control and NAFLD patients at the time of surgery, whereas 18: 2 n-6 and 22: 5 n-6 were $96 \%$ and $369 \%$ higher, respectively; and 22: 5 n3 and 22: 6 n-3 were 74\% and 60\% lower, respectively (Table II). In agreement with data in liver phospholipids, erythrocyte phospholipids exhibited comparable values of n-6 PUFA (Fig. 3A) and n-6 LCPUFA (Fig. 3B) in control and NAFLD patients. Furthermore, in comparison to control values, in obese patients total PUFA and total LCPUFA were $30 \%$ and $35 \%$ lower, respectively (Fig. 3A and 3B); n-3 PUFA and n-3 LCPUFA were $56 \%$ and $59 \%$ lower, respectively (Fig. $3 \mathrm{~A}$ and $3 \mathrm{~B}$ ); the n6/n-3 LCPUFA was $144 \%$ higher (Fig. 3C); and the DHA/DPA n-6 ratio was $91 \%$ lower (Fig. 3D). Association analyses revealed significant correlations in DHA $(r=0.67$; $\mathrm{p}=0.0087)$ and DPA $\mathrm{n}-6(\mathrm{r}=0.79 ; \mathrm{p}=0.0007)$ contents between liver and erythrocyte phospholipids from control and NAFLD patients at the time of surgery. Three months after subtotal gastrectomy, NAFLD patients exhibited erythrocyte phospholipid 
total PUFA and total LCPUFA levels that were $15 \%$ lower (Fig. 3A and 3B) and 20\% lower n-3 PUFA and n-3 LCPUFA (Fig. 3A and $3 \mathrm{~B}$ ) than controls, thus eliciting net $54 \%$ recovery in total PUFA or LCPUFA and $64 \%$ recovery in $n-3$ PUFA or n-3 LCPUFA. In addition, enhancement in erythrocyte phospholipid n-6/n-3 LCPUFA ratio (Fig. 3C) and diminution in that of DHA/DPA n-6 (Fig. 3D) were normalized 3 months after surgery. Compared to control values, the product/precursor ratio (20: $5+$ 22: $5+22: 6) \mathrm{n}-3 / 18: 3 \mathrm{n}-3$ was $72 \%$ and $26 \%$ lower in obese patients at the time of surgery and 3 months after surgery (controls, $32.4 \pm 3.3[\mathrm{n}=7]$ ); obese patients at the time of surgery, $9.0 \pm 2.8$ $[\mathrm{n}=7](\mathrm{p}<0.05$ versus controls and patients 3 months after surgery); obese patients 3 months after surgery, $23.8 \pm 6.4(n=7)$, respectively, thus representing a $64 \%$ recovery (from Table II).

\section{DISCUSSION}

Bariatric surgery is the most effective method of achieving long-term weight control for patients with morbid obesity (Angulo, 2006). Data presented indicate that subtotal gastrectomy in obese patients induced (i) significant weight loss, (ii) reduction in the oxidative stress status evidenced by diminution in serum $\mathrm{F}_{2}$ isoprostane levels, and (iii) improvement in the erythrocyte phospholipid LCPUFA pattern, changes that exhibit a direct correlation with those in liver phospholipids.

Obesity-induced changes in LCPUFA pattern consisted in depletion of $n-3$ LCPUFA, particularly 20: 5 n-3 (EPA), 22: 5 n-3 (DPA), and 22: 6 n-3 (DHA), with enhancement in 22: 5 n-6 (DPA n-6) and n6/n-3 LCPUFA ratios, and reduction in DHA/DPA n-6 ratios, in agreement with

TABLE II

Polyunsaturated fatty acid (PUFA) of erythrocyte phospholipids in control subjects and in obese patients with non-alcoholic fatty liver disease (NAFLD) at the time of surgery (A) and three months after surgery (B)

\begin{tabular}{lccr}
\hline $\begin{array}{l}\text { PUFA } \\
(\mathrm{g} / 100 \mathrm{~g} \text { of FAME })\end{array}$ & $\begin{array}{c}\text { Controls } \\
(\mathrm{n}=7)\end{array}$ & $\begin{array}{c}\text { NAFLD patients }(\mathrm{A}) \\
(\mathrm{n}=7)\end{array}$ & $\begin{array}{c}\text { NAFLD patients }(\mathrm{B}) \\
(\mathrm{n}=7)\end{array}$ \\
\hline $18: 2 \mathrm{n}-6$ & $1.11 \pm 0.13$ & $2.18 \pm 0.58^{\mathrm{b}}$ & $0.97 \pm 0.23^{\mathrm{c}}$ \\
$18: 3 \mathrm{n}-3$ & $0.83 \pm 0.09$ & $1.22 \pm 0.29$ & $0.89 \pm 0.27$ \\
$20: 4 \mathrm{n}-6(\mathrm{ARA})^{\mathrm{e}}$ & $18.4 \pm 0.5$ & $11.9 \pm 1.3^{\mathrm{b}}$ & $18.0 \pm 0.38^{\mathrm{c}}$ \\
$20: 5 \mathrm{n}-3(\mathrm{EPA})^{\mathrm{e}}$ & $3.52 \pm 0.69$ & $2.72 \pm 0.71$ & $1.10 \pm 0.26^{\mathrm{d}}$ \\
$22: 5 \mathrm{n}-6(\mathrm{DPA})^{\mathrm{e}}$ & $1.75 \pm 0.20$ & $8.21 \pm 1.66^{\mathrm{b}}$ & $1.00 \pm 0.20^{\mathrm{c}}$ \\
$22: 5 \mathrm{n}-3(\mathrm{DPA})^{\mathrm{e}}$ & $8.05 \pm 0.91$ & $2.10 \pm 0.63^{\mathrm{b}}$ & $5.10 \pm 0.60^{\mathrm{c}}$ \\
$22: 6 \mathrm{n}-3(\mathrm{DHA})^{\mathrm{e}}$ & $15.3 \pm 1.0$ & $6.17 \pm 0.95^{\mathrm{b}}$ & $15.0 \pm 0.60^{\mathrm{c}}$ \\
\hline
\end{tabular}

Values represent means \pm SEM for the number of patients indicated.

${ }^{\text {a }}$ FAME, fatty acid methyl esters.

${ }^{\mathrm{b}} \mathrm{p}<0.05$ compared to controls (Mann-Whitney test) and obese patients three months after surgery (Wilcoxon test).

${ }^{\mathrm{c}} \mathrm{p}<0.05$ compared to obese patients immediately after surgery (Wilcoxon test).

${ }^{\mathrm{d}} \mathrm{p}<0.05$ compared to controls (Mann-Whitney test).

e ARA, arachidonic acid: EPA, eicosapentaenoic acid; DPA, docosapentaenoid acid; DHA, docosahexaenoic acid. 
earlier studies (Araya et al., 2004; Elizondo et al., 2007). Improvement in the n-3 LCPUFA status of cellular phospholipids by bariatric surgery is associated with reduction in the oxidative stress status, suggesting lower n-3 LCPUFA peroxidation, considering that n-3 LCPUFA are highly susceptible to free-radical attack (Sevanian \& Hochstein, 1985). In agreement with this proposal, weight loss induced by either bariatric surgery (Emery et al., 2003) or dietary sugar restriction (Leclercq et al., 1999) effectively reduces liver CYP2E1 activity, a major free-radical source associated with increased oxidative stress prevailing NAFLD (Lieber, 2004;
Videla et al., 2004a; Orellana et al., 2006). In addition, enhancement in the hepatic desaturase/elongation activity needed for n3 LCPUFA biosynthesis could also play a role in improving n-3 LCPUFA status, as evidenced by the $64 \%$ recovery in the product/precursor ratio $(20: 5+22: 5+22$ : 6) n-3/18: 3 n-3 observed 3 months after subtotal gastrectomy. The latter proposal, however, requires an adequate dietary supply of the essential n-3 LCPUFA precursor 18: 3 n-3 to achieve functional relevance (Baylin et al., 2002). Weight loss-related recovery in the cellular n-3 LCPUFA status may ameliorate the obesityinduced changes in hepatic lipid
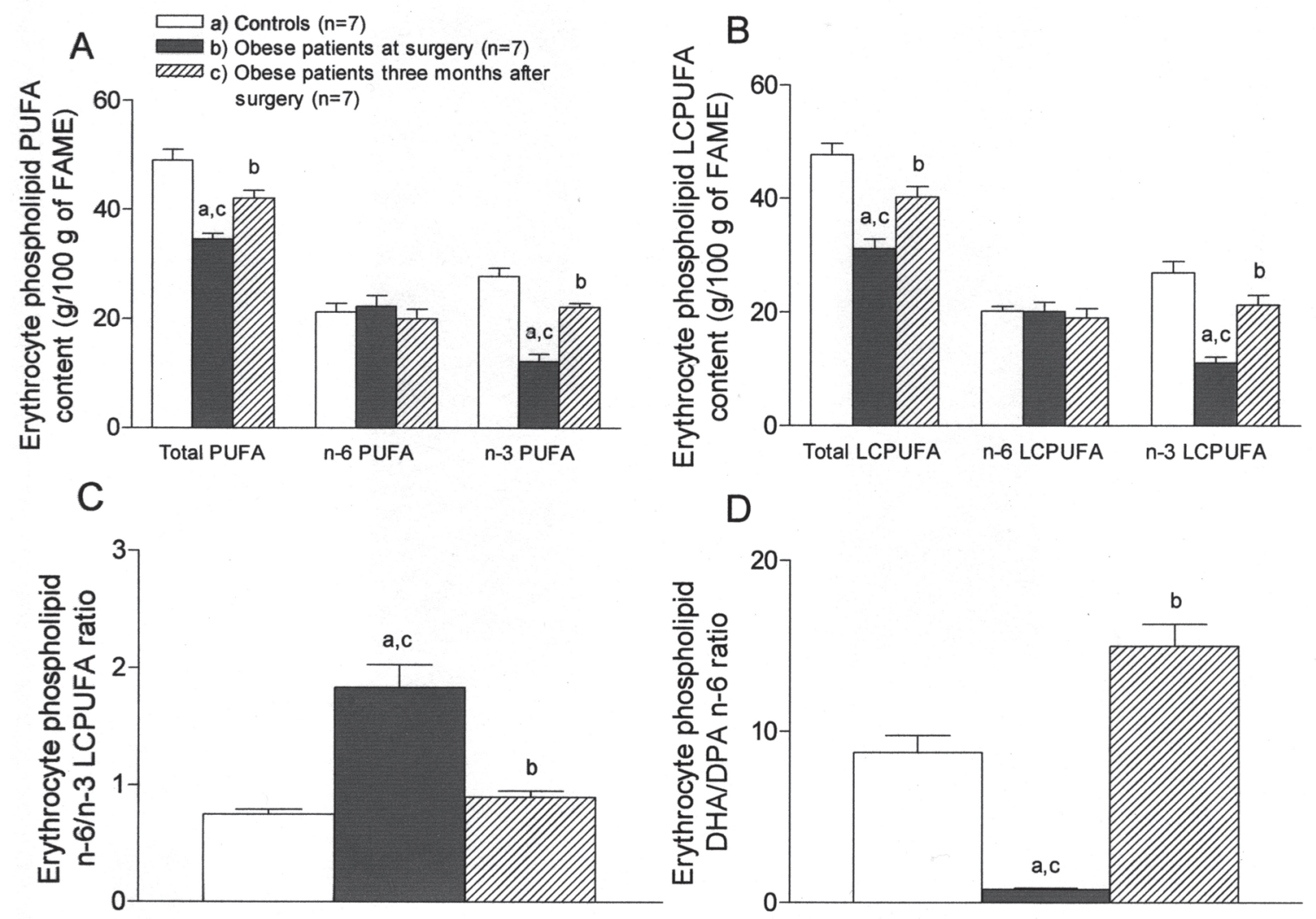

Figure 3: Polyunsaturated fatty acid (PUFA) content (A), long-chain PUFA (LCPUFA) content (B), n-6/n-3 LCPUFA ratio (C), and docosahexaenoic acid (DHA)/docosapentaenoic acid (DPA n6) ratio (D) in erythrocyte phospholipids from control subjects and obese patients with nonalcoholic fatty liver disease at the time of surgery and three months after surgery. Values represent means \pm SEM for the number of patients indicated in parenthesis. Significant differences between mean values are indicated by the letters identifying each group: ${ }^{a} p<0.05$ versus controls (MannWhitney $\mathrm{U}$ test); ${ }^{\mathrm{b}} \mathrm{p}<0.05$ versus obese patients at the time of surgery (Wilcoxon test); ${ }^{\mathrm{c}} \mathrm{p}<0.05$ versus obese patients three months after surgery (Wilcoxon test). For abbreviations, see legend to Figure 2. 
metabolism leading to steatosis (Araya et al., 2004; Videla et al., 2004a), as n-3 LCPUFA suppress lipogenic gene expression and induce that of genes involved in lipid oxidation (Clarke, 2004; Delarue et al., 2004). This view is in agreement with the significant decrease in the amount of hepatic steatosis reported in obese patients at variable times (10 to 36 months) after bariatric surgery (Dixon et al., 2004; Mattar et al., 2005; Clark et al., 2005; Mathurin et al., 2006; Klein et al., 2006; Jaskiewicz et al., 2006).

Cellular depletion of n-3 LCPUFA, particularly DHA, observed in n-3 fatty acid-deficient animals (Connor et al., 1990; Greiner et al., 2003), human infants fed vegetable oil-based formulas (Makrides et al., 1994), or in obese NAFLD patients (Elizondo et al., 2007), is accompanied by increased n-6 PUFA levels, particularly 22: 5 n-6 (DPA n-6), leading to diminished DHA/DPA n-6 ratios. This compensatory mechanism aimed to conserve polyunsaturation of membrane phospholipids (Moriguchi et al., 2001; Leonard et al., 2004) is not fully operative in obesity, as evidenced by the lower levels of total PUFA found in liver and erythrocyte phospholipids from obese patients compared to control values. However, DHA/DPA n-6 ratios in obese patients 3 months after bariatric surgery are comparable to those in control subjects. The latter finding suggests that weight loss effectively recovers polyunsaturation of phospholipids, which may lead to adequate membrane fluidity and improvement of membrane-mediated processes, such as insulin signaling (Lombardo and Chico, 2006), thus lowering the prevalence of the metabolic syndrome (Mattar et al., 2005; Klein et al., 2006; Jaskiewicz et al., 2006).

Collectively, data presented indicate that subtotal gastrectomy-induced weight loss in obese NAFLD patients has beneficial effects manifested by improvement in the n3 LCPUFA status, associated with the amelioration of biomarkers of oxidative stress, n-3 LCPUFA biosynthetic capacity, and membrane polyunsaturation. These effects occur in patients that have lost $21 \%$ of their initial body weight during the first
3 months after surgery, in agreement with the observation that most weight loss induced by bariatric surgery occurs within the first year (Klein et al., 2006; Angulo, 2006). The early effects on cellular PUFA pattern and systemic oxidative stress status achieved by subtotal gastrectomy and the normalization of the major metabolic abnormalities of NAFLD elicited by other bariatric surgery procedures after longer periods (Klein et al., 2006; Mathurin et al., 2006) point to weight loss as a central therapeutic issue in the improvement or resolution of the obesity-related complications. Moreover, weight loss may be combined with antioxidants, n-3 LCPUFA (Videla et al., 2006), and/or innocuous cytochrome P450 2E1 inhibitors (Lieber, 2004) to minimize alterations in redox status, membrane polyunsaturation, and insulin signaling involved in hepatic steatosis, which otherwise may lead to disease progression.

\section{ACKNOWLEDGEMENTS}

This work was supported by grant 1060105 from FONDECYT (Chile).

\section{REFERENCES}

ANGULO P (2006) NAFLD, obesity, and bariatric surgery. Gastroenterology 130: 1848-1852

ARAYA J, RODRIGO R, ORELLANA M, RIVERA G (2001) Red wine raises HDL and preserves long-chain polyunsaturated fatty acids in rat kidney and erythrocytes. Br J Nutr 86: 189-195

ARAYA J, RODRIGO R, VIDELA LA, THIELEMANN L, ORELLANA M, PETTINELLI P, PONIACHIK J (2004) Increase in long-chain polyunsaturated fatty acid $n-6 / n-3$ ratio in relation to hepatic steatosis in patients with non-alcoholic fatty liver disease. Clin Sci (London) 106: 635-643

BAYLIN A, KABAGAMBE EK, SILES X, CAMPOS H (2002) Adipose tissue biomarkers of fatty acid intake. Am J Clin Nutr 76: 750-757

BLIGH EG, DYER WJ (1959) A rapid method of total lipid extraction. Can J Biochem Physiol 37: 911-917

CLARK JM, ALKHURAISHI AR, SOLGA SF, ALLI P, DIEHL AM, MAGNUSON TH (2005) Roux-en-Y gastric bypass improves liver histology in patients with non-alcoholic fatty liver disease. Obes Res 13: 11801186

CLARKE SD (2004) The multi-dimensional regulation of gene expression by fatty acids: Polyunsaturated fats as nutrient sensors. Curr Opin Lipidol 15: 13-18 
CONNOR WE, NEURINGER M, LIN DS (1990) Dietary effects on brain fatty acid composition: The reversibility of n-3 fatty acid deficiency and turnover of docosahexaenoic acid in the brain, erythrocytes, and plasma of rhesus monkeys. J Lipid Res 31: 237-247

DAS UN (2005) A defect in the activity of Delta6 and Delta5 desaturases may be a factor predisposing to the development of insulin resistance syndrome. Prostaglandins Leukot Essent Fatty Acids 72: 343-350

DAS K, KAR P (2005) Non-alcoholic steatohepatitis. J Assoc Physicians India 53: 50-59

DELARUE J, LEFOLL C, CORPOREAU C, LUCAS D (2004) n-3 Long chain polyunsaturated fatty acids: A nutritional tool to prevent insulin resistance associated to type 2 diabetes and obesity? Reprod Nutr Dev 44: 289-299

DIXON JB, BHATHAL PS, HIGHES NR, OBRIEN PE (2004) Nonalcoholic fatty liver disease: Improvement in liver histological analysis with weight loss. Hepatology 39: 1647-1654

ELIZONDO A, ARAYA J, RODRIGO R, PONIACHIK J, CSENDES A, MALUENDA F, DÍAZ JC, SIGNORINI C, SGHERRI C, COMPORTI M, VIDELA LA (2007) Polyunsaturated fatty acid pattern in liver and erythrocyte phospholipids from obese patients. Obesity 15: 24-31

EMERY MG, FISHER JM, CHIEN JY, KHARASCH ED, DELLINGER EP, KOWDLEY KV, THUMMEL KE (2003) CYP2E1 activity before and after weight loss in morbidity obese subjects with non-alcoholic fatty liver disease. Hepatology 38: 428-435

FERNÁNDEZ V, VIDELA LA (1996) Biochemical aspects of cellular antioxidant systems. Biol Res 29: 177-182

GREINER RS, CATALÁN JN, MORIGUCHI T, SALEM N JR (2003) Docosapentaenoic acid does not completely replace DHA in n-3 FA-deficient rats during early development. Lipids 38: 431-435

HUERTAS JR, PALOMINO N, OCHOA JJ, QUILES JL, RAMÍREZ-TORTOSA MC, BATTINO M, RONLES R, MATAIX J (1998) Lipid peroxidation and antioxidants in erythrocyte membranes of full-term and preterm newborns. Biofactors 8: 133-137

JASKIEWICZ K, RACZYNSKA S, RZEPKO R, SLEDZINSKI Z (2006) Nonalcoholic fatty liver disease treated by gastroplasty. Dig Dis Sci 51: 21-26

KLEIN S, MITTENDORFER B, EAGON JC, PATTERSON B, GRANT L, FEIRT N, SEKI E, BRENNER D, KORENBLAT K, MCCREA J (2006) Gastric bypass surgery improves metabolic and hepatic abnormalities associated with non-alcoholic fatty liver disease. Gastroenterology 130: 1564-1572

LECLERCQ I, HORSMANS Y, DESAGER JP, PAUWELS S, GEUBEL AP (1999) Dietary restriction of energy and sugar results in a reduction in human cytochrome P450 2E1 activity. Br J Nutr 82: 257-262

LEONARD AE, PEREIRA SL, SPRECHER H, HUANG YS (2004) Elongation of long-chain fatty acids. Prog Lipid Res 43: 36-54

LIEBER CS (2004) The discovery of the microsomal ethanol oxidizing system and its physiologic and pathologic role. Drug Metab Rev 36: 511-529

LOMBARDO YB, CHICO AG (2006) Effects of dietary polyunsaturated n-3 fatty acids on dyslipidemia and insulin resistance in rodents and humans. A review. J Nutr Biochem 17: 1-13

MAKRIDES M, NEUMAN MA, BYARD RW, SIMMER K, GIBSON RA (1994) Fatty acid composition of brain, retina, and erythrocytes in breast- and formulafed infants. Am J Clin Nutr 60: 189-194

MATHURIN P, GONZÁLEZ F, KERDRAON O LETEURTRE E, ARNALSTEEN L, HOLLEBECQUE A, LOUVET A, DHARANCY S, COCQ P, JANY T, BOITARD J, DELTENRE P, ROMON M, PATTOU F (2006) The evolution of severe steatosis after bariatric surgery is related to insulin resistance. Gastroenterology 130: 1617-1624

MATTAR SG, VELCU LM, RABINOVITZ M, DEMETRIS AJ, KRASINSKAS AM, BARINASMITCHELL E, EID GM, RAMANATHAN R, TAYLOR DS, SCHAUER PR (2005) Surgicallyinduced weight loss significantly improves nonalcoholic fatty liver disease and the metabolic syndrome. Ann Surg 242: 610-620

MATTHEWS DR, HOSKER JP, RUDENSKI AS, NAYLOR BA, TREACHER DF, TURNER RC (1985) Homeostasis model assessment: Insulin resistance and b-cell function from fasting plasma glucose and insulin concentration in man. Diabetologia 28: 412-419

MORIGUCHI T, LOEWKE J, GARRISON M, CATALÁN JN, SALEM N Jr (2001) Reversal of docosahexaenoic acid deficiency in the rat brain, retina, liver, and serum. J Lipid Res 42: 419-427

ORELLANA M, RODRIGO R, VARELA N, ARAYA J, PONIACHIK J, CSENDES A, SMOK G, VIDELA LA (2006) Relationship between in vivo chlorzoxazone hydroxylation, hepatic cytochrome P450 2E1 content and liver injury in obese non-alcoholic fatty liver disease patients. Hepatol Res 34: 57-63

RUIZ-GUTIÉRREZ V, CERT A, RÍOS JJ (1992) Determination of phospholipid fatty acid and triacylglycerol composition of rat caecal mucosa. J Chromatogr 575: 1-6

SALTIEL AR, KHAN CR (2001) Insulin signaling and the regulation of glucose and lipid metabolism. Nature 414: 799-806

SEVANIAN A, HOCHSTEIN P (1985) Mechanisms and consequences of lipid peroxidation in biological systems. Ann Rev Nutr 5: 365-390

SIES H, STAHL W, SEVANIAN A (2005) Nutritional, dietary and postprandial oxidative stress. J Nutr 135: 969-972

SIGNORINI C, COMPORTI M, GIORGI G (2003) Ion trap tandem mass spectrometric determination of $\mathrm{F}_{2}-$ isoprostanes. J Mass Spectrom 38: 1067-1074

SKIPSKI VP, PETERSON RF, BARCLAY M (1964) Quantitative analysis of phospholipids by thin-layer chromatography. Biochem J 90: 374-378

VIDELA LA, RODRIGO R, ARAYA J, PONIACHIK J (2004a) Oxidative stress and depletion of hepatic longchain polyunsaturated fatty acids may contribute to non-alcoholic fatty liver disease. Free Radic Biol Med 37: $1499-1507$

VIDELA LA, RODRIGO R, ORELLANA M, FERNÁNDEZ V, TAPIA G, QUIÑÓNEZ L, VARELA $\mathrm{N}$, CONTRERAS J, LAZARTE R, CSENDES A, ROJAS J, MALUENDA F, BURDILES P, DÍAZ JC, SMOK G, THIELEMANN L, PONIACHIK J (2004b) Oxidative stress-related parameters in the liver of nonalcoholic fatty liver disease patients. Clin Sci (London) 106: $261-268$

VIDELA LA, RODRIGO R, ARAYA J, PONIACHIK J (2006) Insulin resistance and oxidative stress interdependency in non-alcoholic fatty liver disease. Trends Mol Med 12: 555-558 